EGTRIB Journal

JOURNAL OF

THE EGYPTIAN SOCIETY OF TRIBOLOGY

VOLUME 18, No. 4, October 2021, pp. 66-78 ISSN 2090 - 5882

(Received September 27. 2021, Accepted in final form September 29. 2021)

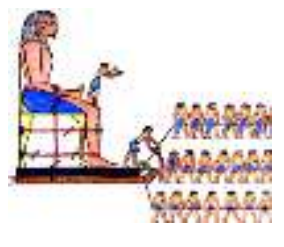

jest.journals.ekb.eg

\title{
OPTIMIZATION OF WEAR RESISTANCE AND AMORPHOUS CONTENT FOR FECRMOCB-MG COMPOSITE BY USING FUZZY LOGIC CONTROL SYSTEM
}

\author{
Maha M.A. Lashin ${ }^{1,2}$, Mahmoud Z. Ibrahim ${ }^{3}$, Ahmad M. Makadi ${ }^{4}$, Mohamed M. Hedaya \\ ${ }^{1}$ College of Engineering, Princess Nourah Bint Abdulrahaman University, Riyadh, 11564, Saudi Arabia, \\ ${ }^{2}$ Mechanical Engineering Department, Faculty of Engineering Shoubra, Banha University, Egypt, \\ ${ }^{3,5}$ Department of Mechanical Engineering, Faculty of Engineering, Ain Shams University, Cairo, 11517, Egypt, \\ ${ }^{4}$ Department of Manufacturing Engineering Technology, College of Technological Studies, PAAET, Kuwait.
}

ABSTRACT

Titanium alloy (Ti6Al4V), stainless steel, and cobalt chromium alloy (CoCr) are biomaterials used biomedical implants with limited acceptable biocompatibility because their low wear resistance. A ductile metallic low-nickel stainless steel alloy with metallic glass coating layer produces wear resist composite material. In this work, fuzzy logic control system (FLC) using for optimizing wear resistance and amorphous content of Fe-based MG (metallic glass) composite, papered its substrate surface by silicon carbide 240 grit sandpaper, and laser cladded with nickel free stainless steel. FLC controlling energy, overlap, spot size, and scanning for optimization purpose. The range of tolerance between experimental and fuzzy system results are $1 \%$ to $15 \%$.

\section{KEYWORD}

Metallic alloy and glass, scanning speed, overlap, spot size, energy, wear resistance, amorphous content, fuzzy control system

\section{INTRODUCTION}

Laser cladding is a material deposition technique in which a powdered or wire feedstock material is melted and solidified using a laser (light amplification by stimulated emission of radiation) to coat a substrate or produce a near-net form part, [1]. It is used to improve mechanical qualities, increase corrosion resistance, repair damaged parts, and fabricate metal composites, among other things, [2].

Laser cladding powder is usually metallic in nature and is injected into the system by either lateral nozzle. Melting occurs when the metallic powder stream interacts with the laser, which is known as the melt pool as shown in Fig. 1, [3]. This is placed onto a substrate, which is then moved to allow the melt pool to solidify, resulting in a solid metal track. A CAD system directs the motion of the substrate by interpolating solid objects into a sequence of tracks, resulting in the desired component at the conclusion of the trajectory, [4]. 


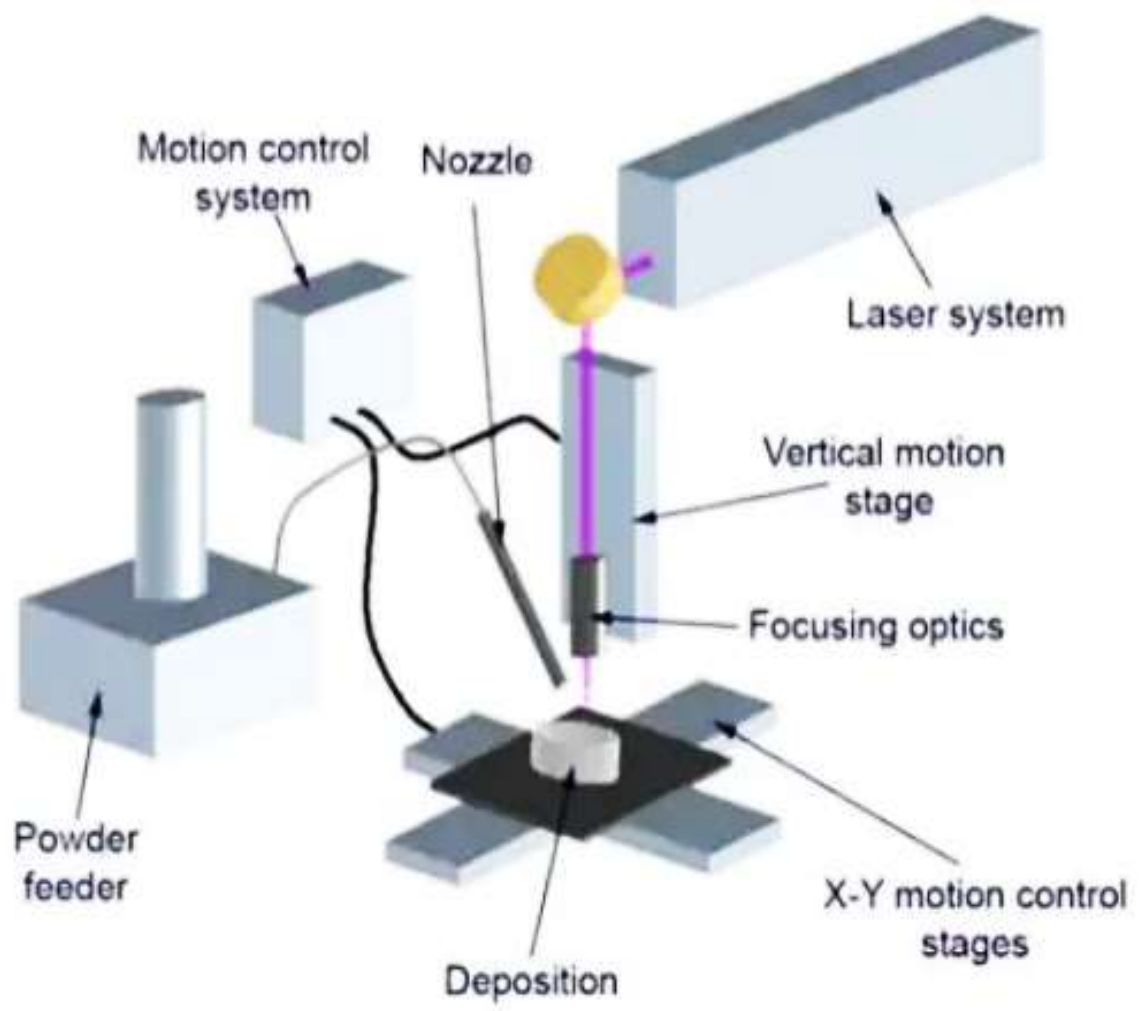

Fig. 1 Mechanism of Laser Cladding.

Some of the important process parameters of laser cladding are laser power, laser focal point, substrate velocity, powder injection, material of substrate and powder [5]. One of the essential parameters in laser cladding process is the scanning speed, which affects the amount of energy that is absorbed by powder, clad height, and clad quality. An enhanced fuzzy system suggested to build the process' fuzzy inverse dynamic model for comparing its performance with the actual measured scanning speed suggestion is used to build the process' fuzzy inverse dynamic model. Results of the developed fuzzy model makes them suitable for real-time control application, [6].

Increasing corrosion and wear in valve sealing surface because of high temperature and high-pressure corrosion environment were the response of preparing nickel-based tungsten carbide alloy layer surface substrate material by laser cladding process. A fuzzy system designed and implemented for optimum macroscopic quality, microstructure, microhardness, anti-wear performance, oxidation resistance, compactness and corrosion resistance related to effects of laser power, scanning speed, powder feeding rate, and WC content on the alloy. The results were stratified and nearest the experiments results, [7].

As shown in the previous literature review, there is very few number research that has focused on using fuzzy control system for optimizing characteristics of material surface' produced from laser cladded process. In the presented work a novel methodology depending on fuzzy control system used for optimizing surface wear rate and amorphous content of Febased metallic glass composite material through controlled machining parameters (scanning speed and overlap) and characteristics of laser beam (its spot size and energy). 
In the presented work, the fuzzy logic control system designing and structing for implementing it on machining parameters and laser beam of cladding machine parameters to optimize values of surface wear rate and amorphous content of Fe-based MG samples. Sequences of work through the presented paper summarized in Fig. 1.

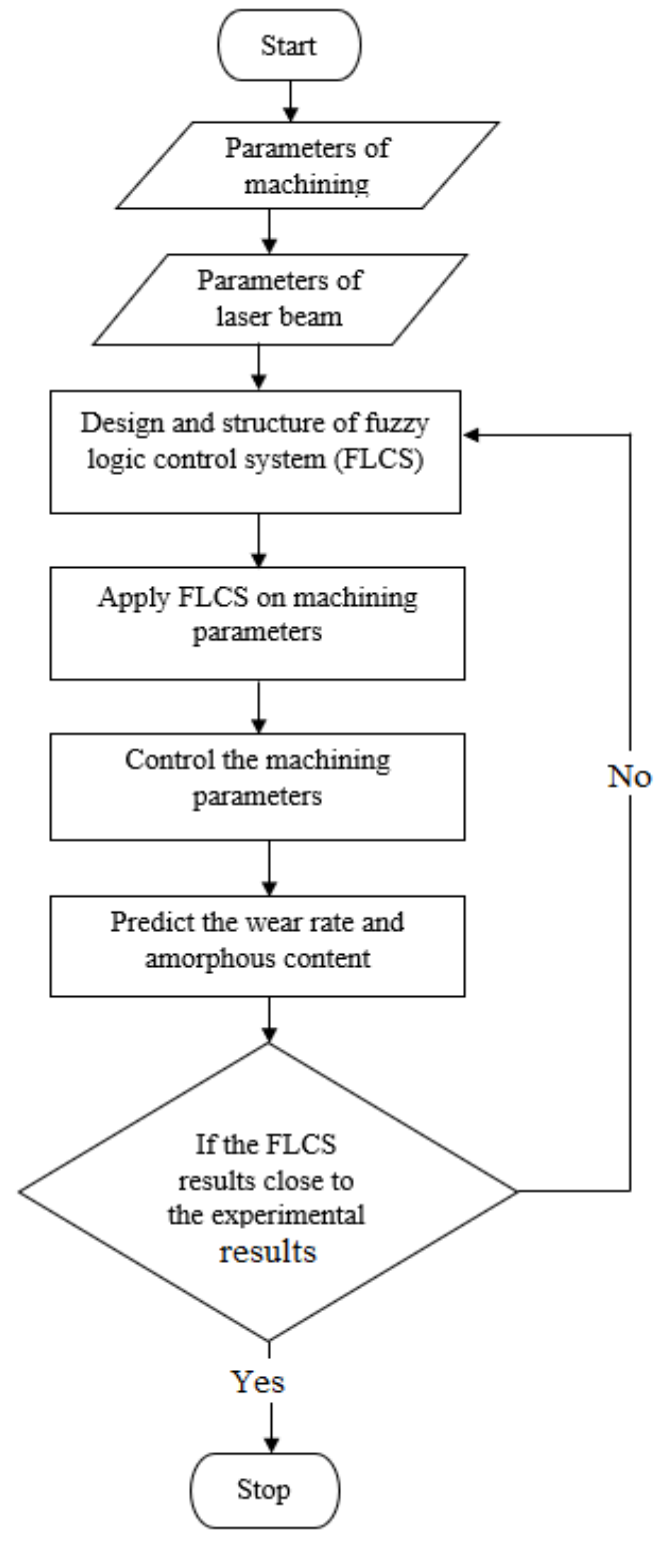

Fig. 2 Flow chart of FLCS of wear rate and amorphous content detection.

Preparing Data

Data used to design and struct fuzzy logic control system come from experimental work of laser cladding process [8]. Nine samples $30 \times 30 \times 3 \mathrm{~mm}$ of nickel-free stainless-steel highnitrogen coated with amorphous powder through laser cladding process after polished its substrates by $\mathrm{SiC}$ sandpaper $\mathbf{2 4 0}$ grit, cleaned, and dried with deionized water-ethanol and ambient air, respectively. Those samples were used experimentally for testing its wear rate and amorphous content. The parameters that affected on laser cladding process included machining parameters (direction of cladding (or scanning direction), scanning speed, and 
overlap) and characteristics of laser beam (its spot size or spot dimension and energy) as shown in Fig. 3. In the presented work laser scanning direction, spot size, laser beam energy, and overlap nominations studied and controlled to predict and optimize surface characteristics' wear resistance and amorphous content.

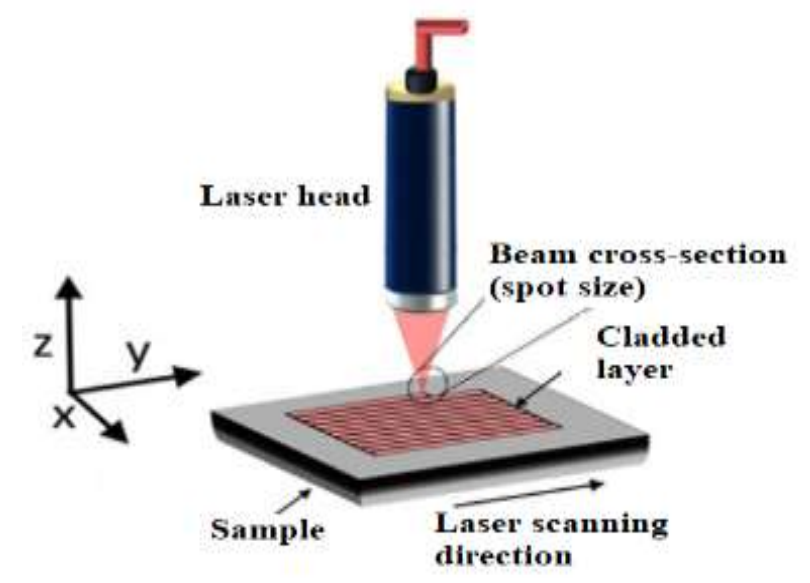

(a) Laser Cladded Process Parameters

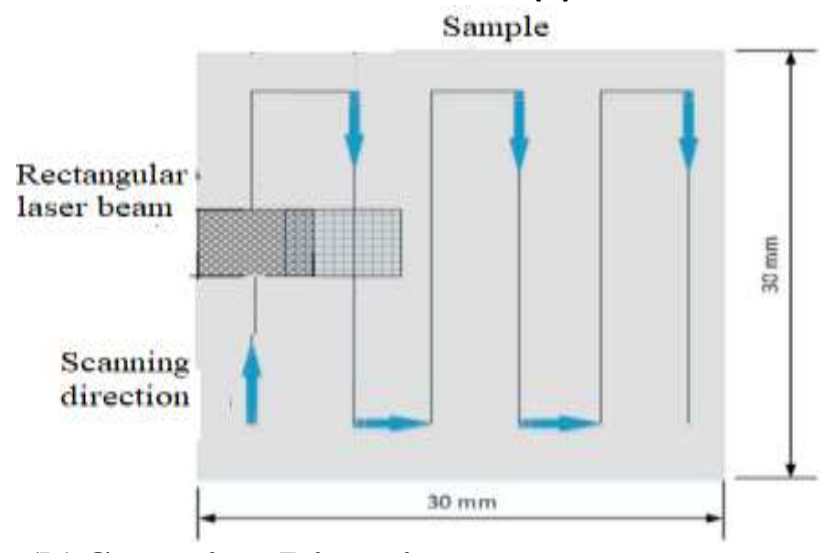

(b) Scanning Direction

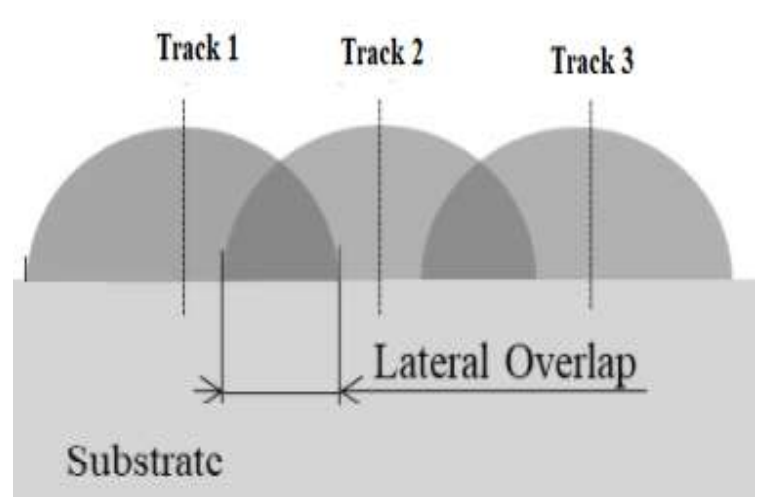

(c) Overlap

Fig. 3 Parameters of Laser Cladding Process

Laser scanning direction had a significant effect on the gradient distribution [9]. Increasing scanning speed causes decreasing thickens of cladded layer [10]. Overlapping come from overhanging the cladded tracks, symmetry of overlapping increase smoothing of cladded layers [11]. Laser beam radial distance or spot size can be decreasing mechanical properties of the laser cladded material [12]. Laser cladding process generally done with continuous beam laser with different types of kilowatts, the beam out of the laser is focused onto the part to clad the surface for generating the required energy density [13].

Experimental parameters of FeCrMoCB MG samples includes scanning speed (mm/s), overlap (\%), spot size $(\mathrm{mm})$, and specific energy $(\mathrm{J} / \mathrm{mm} 3)$ write in detail as in table 1.

\section{Fuzzy Logic Control System (FCLS)}

FLCS is a control system that based on mathematical system for analyzing analog input values in terms of continuous logical on discrete values of either 1 or 0 (true or false, respectively). An input stage, a processing stage, and an output stage are part of the Fuzzy control system. The input stage maps the necessary membership functions known as fuzzy 
sets for converting the crisp input values to a fuzzy value through fuzzification process. Each appropriate rule is invoked by the processing stage and produces a result for each, then combines the rules' outcomes. Finally, the output stage transforms the combined outcome back into a particular output value of the control through defuzzfication process [14].

Table 1: Parameters of experimental work [1]

\begin{tabular}{ccccc} 
& \multicolumn{4}{c}{ Parameters } \\
\cline { 2 - 5 } Samples & $\begin{array}{l}\text { Scanning } \\
\text { Speed }(\mathbf{m m} / \mathbf{s})\end{array}$ & Overlap (\%) & Spot size $(\mathbf{m m})$ & $\begin{array}{c}\text { Energy } \\
\left(\mathbf{J} / \mathbf{m m}^{3}\right)\end{array}$ \\
\hline 1 & 20 & 50 & $4 \times 4$ & 6.25 \\
\hline 2 & 20 & 35 & $4 \times 6$ & 6.25 \\
\hline 3 & 20 & 25 & $4 \times 8$ & 6.25 \\
\hline 4 & 25 & 35 & $4 \times 4$ & 5 \\
\hline 5 & 25 & 25 & $4 \times 6$ & 5 \\
\hline 6 & 25 & 50 & $4 \times 8$ & 4.16 \\
\hline 7 & 30 & 25 & $4 \times 4$ & 4.16 \\
\hline 8 & 30 & 50 & $4 \times 6$ & 4.16 \\
\hline 9 & 30 & 35 & $4 \times 8$ &
\end{tabular}

\subsection{Struct a Fuzzy Models}

The components of the FLC including fuzzification step to convert the crisp input values into fuzzy values. Fuzzy knowledge base used membership function to define the inputs outputs of fuzzy system and store relation between them through fuzzy rule base (If-Then) form to decide the fuzzy system decisions depending on inference engine [15]. Converting fuzzy values that come from inference engine into crisp values done in defuzzifier step as shown in Fig. 4.

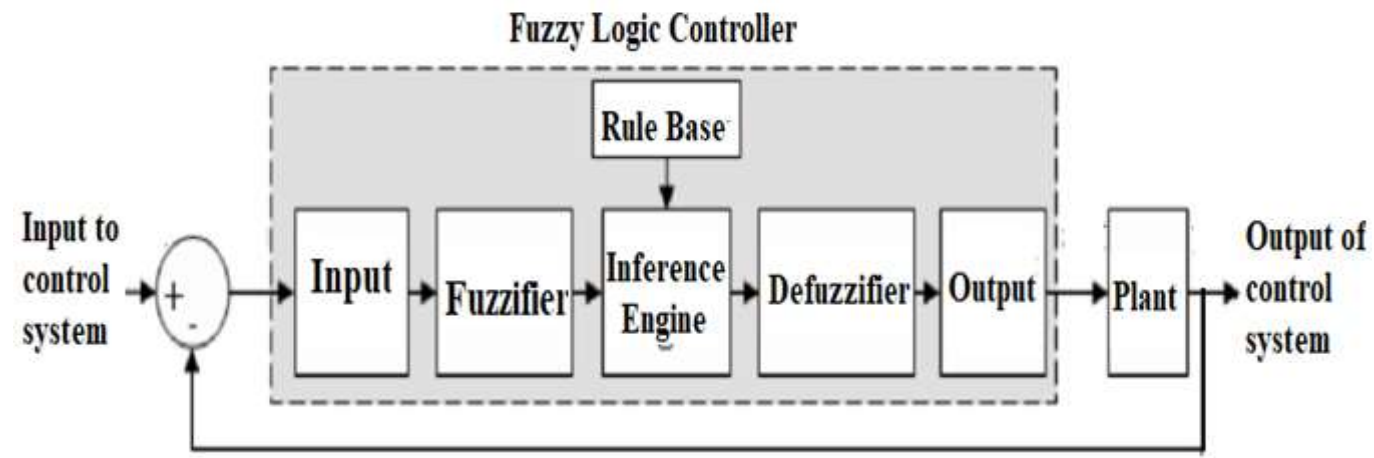

Fig. 4 Architecture of Fuzzy Logic Controller.

Two fuzzy logic control systems (wear rate and amorphous content fuzzy systems) were designed with four inputs and one output for each of them, then implemented for study wear rate and amorphous content for FeCrMoCB MG samples. Fuzzy sytems inputs were scanning speed, overlap, spot size, and energy where the output were wear rate for one and amorphous content for athor.

\subsection{Wear Rate and Amorphous Content Fuzzy Systems}

Scanning speed within $(20-30) \mathrm{mm} / \mathrm{s}$, overlap within $(25-50) \%$, spot size within $(4 \times 4-4 \times 8)$ $\mathrm{mm}$ and energy within $(4.16-6.26) \mathrm{J} / \mathrm{mm}^{3}$, were the inputs of wear rate fuzzy control system 
and amorphous content fuzzy system to determine maximum and minmum value for its output ( wear rate and amorphous content). Figure 5 provides the structural of the fuzzy logic systems that has been designed and applied to wear rate $(a, b)$ and amorphous content (c, d).

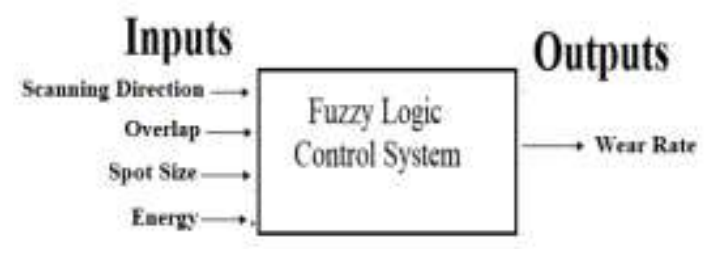

(a)

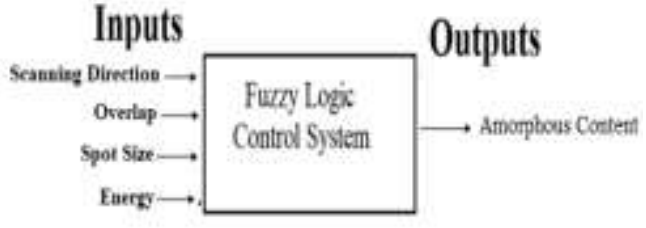

(c)

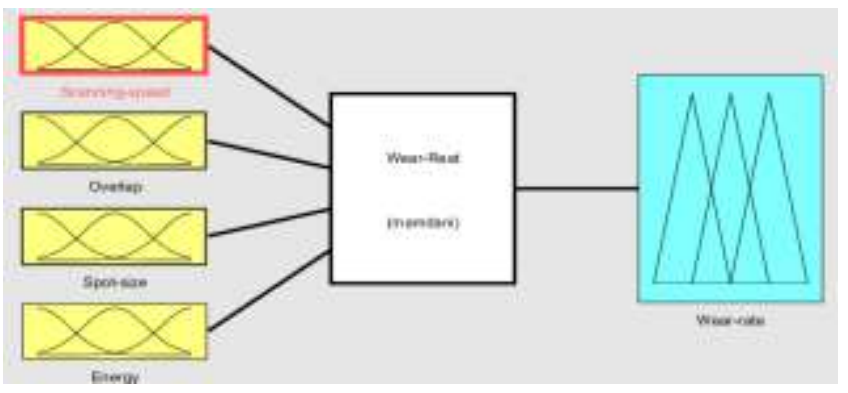

(b)

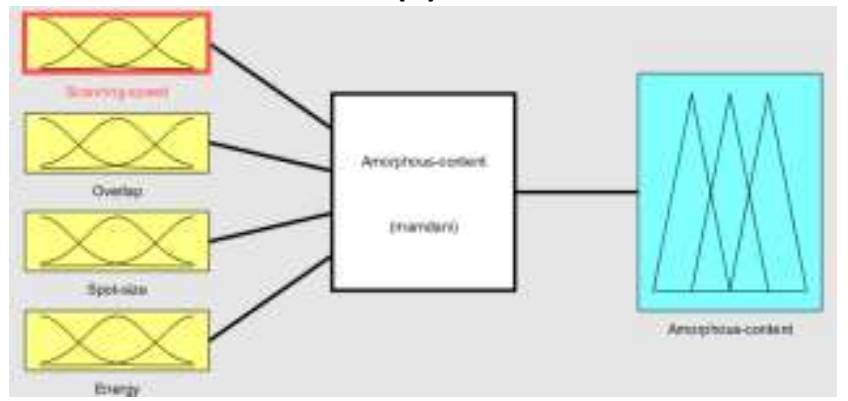

(d)

Fig. 5 (a, b) Wear Rate Fuzz Logic Control System and (c, d) Amorphous Content Fuzzy System.

1.2.1. Inputs - Output Membership Functions of Wear Rate and Amorphous Content Fuzzy System

For points a1, a2, and a3 the triangular membership function as shown in Fig. 6 in fuzzy system $A=\left(a_{1}, a_{2}, a_{3}\right)$ represented as increasing function (a1 to $\left.a_{2}\right)$ and decreasing function (a2 to a3) that can write as [16];

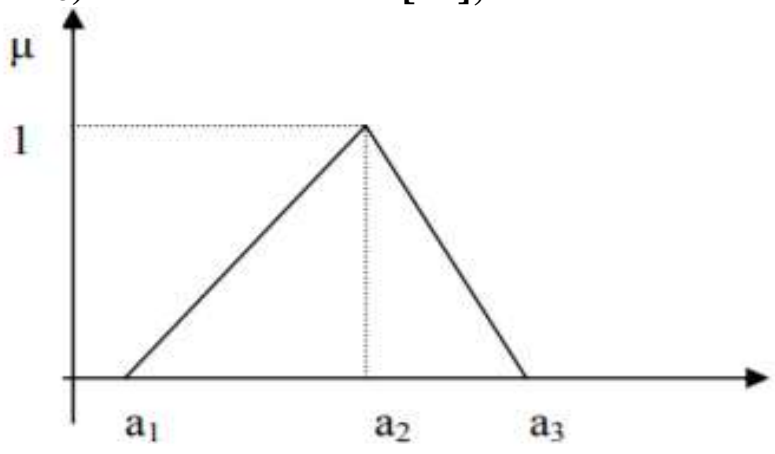

$$
\mu_{A}(x)=\left\{\begin{array}{cl}
0 & \text { for } x<a_{1} \\
\frac{x-a_{1}}{a_{2}-a_{1}} & \text { for } a_{1} \leq x \leq a_{2} \\
\frac{a_{3}-x}{a_{3}-a_{2}} & \text { for } a_{2} \leq x \leq a_{3} \\
0 & \text { for } x>a_{3}
\end{array}\right.
$$

Fig. 6: Triangular Membership Function.

The triangular membership function of wear rate and amorphous content fuzzy systems used to fuzzifier inputs (scanning speed, overlap, spot size, and energy) in three values of fuzzy sets (Low, Medium, and High) as appeared in Fig. 7. Triangular membership function 
fuzzification the inputs of fuzzy systems as shown in Fig. 8 (a), (b), (c), and (d) respectively. Table 2 explains the low, mdium, and high levels of fuzzy systems inputs.

Input to fuzzy system (scanning speed or overlap or spot size or enrgy)
Overlap Low

Overlap Medium

Overlap High

Fig. 7: Fuzzification of Fuzzy Systems Inputs

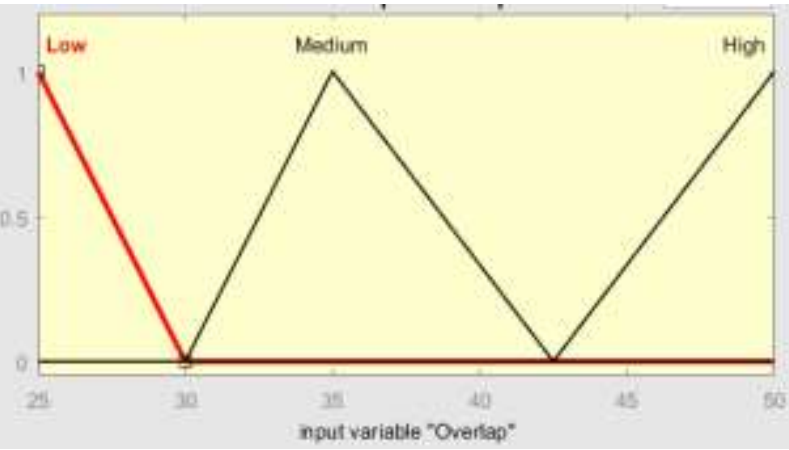

(a)

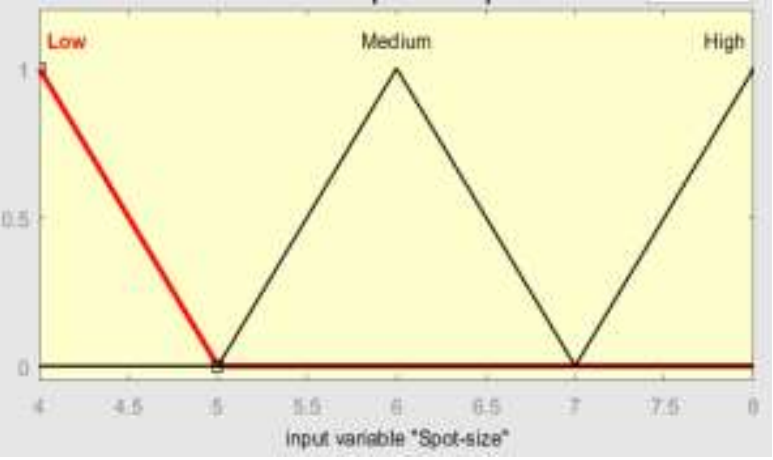

(c)

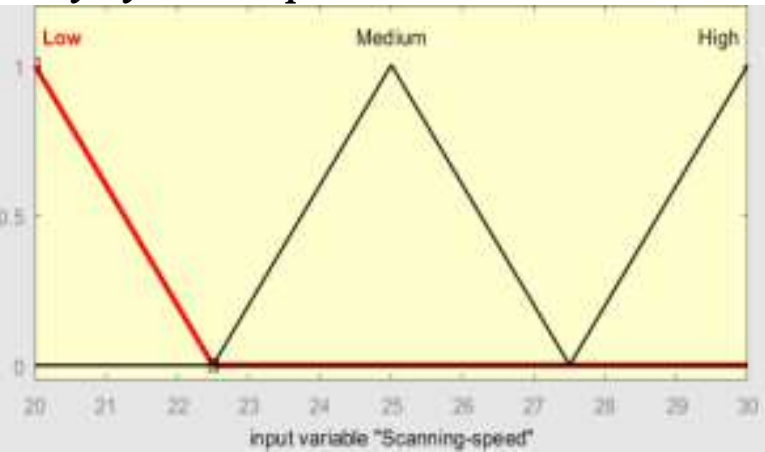

(b)

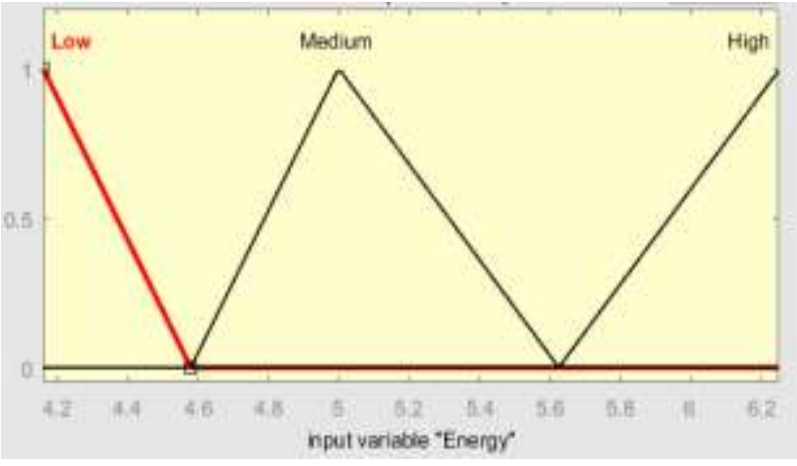

(d)

Fig. 8 Triangular Membership Functions for Fuzzy Systems Inputs (a) Overlap, (b) Scanning speed, (c ) Spot size, and (d) Energy.

Table 2. Membership Functions of Fuzzy Systems Inputs

\begin{tabular}{llrrr} 
Fuzzy System Inputs & Membership Function & \multicolumn{3}{c}{ Range of Inputs } \\
\cline { 3 - 5 } Variables & Used & Low & Medium & High \\
\hline Scanning Speed & Triangular MF & $20-24$ & $24-27.5$ & $27.5-30$ \\
\hline Overlap & Triangular MF & $20-30$ & $30-42.5$ & $42.5-50$ \\
\hline Spot size & Triangular MF & $4 \times 4-4 \times 5$ & $4 \times 5-4 \times 7$ & $4 \times 7-4 \times 8$ \\
\hline Energy & Triangular MF & $4.2-4.6$ & $4.6-5.6$ & $5.6-6.2$ \\
\hline
\end{tabular}

Applied defuzzification step to get fuzzy system decisions (output of fuzzy system) through number of rules (if-then rules) used for transforming variables into fuzzy system for defining fuzzy sets and acceptable membership degrees, Fig. 9 (a, c). Triangular membership function used to defuzzied the wear rate and amorphous content with low, medium, and high value as shown in Fig. 9 (b, d). 


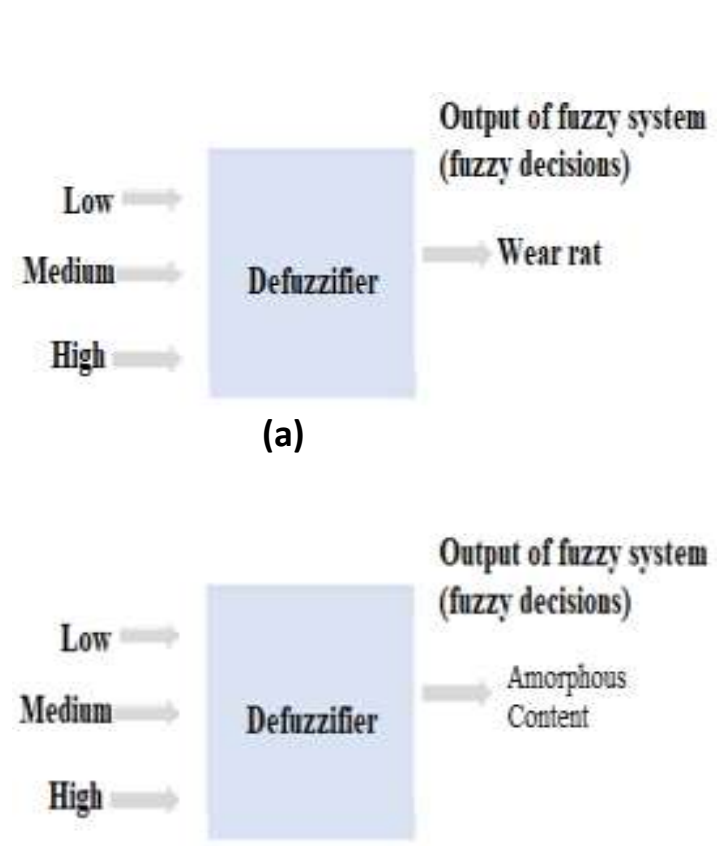

(c)

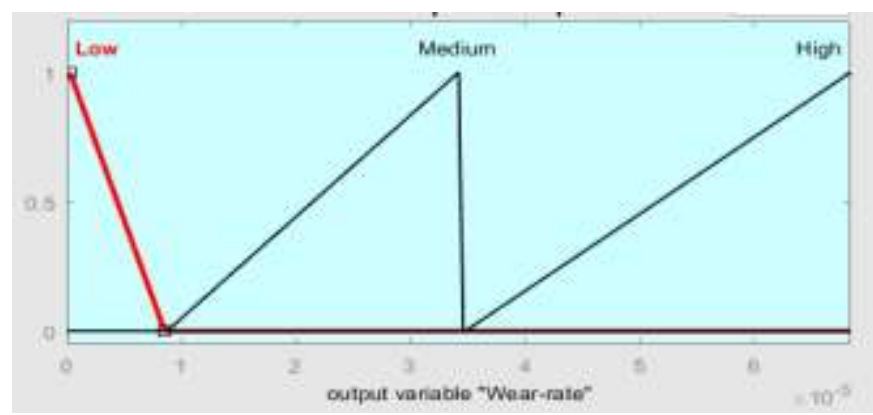

(b)

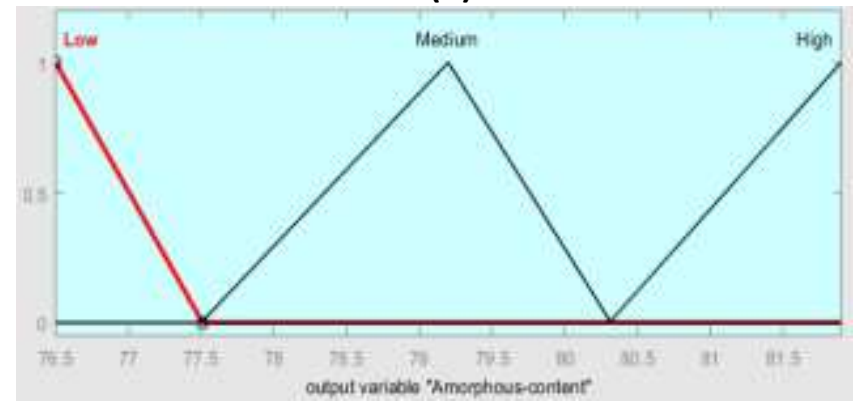

(d)

Fig. 9 (a, b) Deuzzification Step and Output of Wear Rate Fuzzy System, (c, d)

Deuzzification Step and Output of Amorphous Content Fuzzy System.

Table 3. Membership Functions of Fuzzy System Output

\begin{tabular}{llcccc}
\hline Fuzzy Systems & Membership & \multicolumn{4}{c}{ Range of Inputs } \\
\cline { 3 - 6 } Outputs Variables & Function used & $\begin{array}{c}\text { Scanning } \\
\text { Speed }\end{array}$ & Overlap & Spot Size & Energy \\
\hline $\begin{array}{l}\text { Wear rate }- \\
\text { Amorphous content }\end{array}$ & Triangular MF & $20-30$ & $20-50$ & $4 \times 4-4 \times 8$ & $4.2-6.2$ \\
\hline
\end{tabular}

\subsubsection{If - Then Rules of Wear Rate and Amorphous Content Fuzzy Systems}

Fuzzy rules or If - Then rules used to join between inputs and outputs of the designed systems. In the presented wera rate fuzzy system and amorphous content fuzzy system, the fuzzy rules used to explain changes in wear rate and amorphous content of samples surface as a result of changing in machining conditions and laser beam characterstices (scannin speed, overlap, spot size, and energy) as shown in table 4.

Table 4: Wear Rate and Amorphous Content Fuzzy Systems If - Then Rules

Fuzzy Rules (If - Then rules)

If (Scanning-speed is Low) and (Overlap is High) and (Spot-size is Low) and (Energy is High) then (Wear-rate is High) (1)

If (Scanning-speed is Low) and (Overlap is Medium) and (Spot-size is Medium) and (Energy is High) then (Wear-rate is Medium) (1)

If (Scanning-speed is Low) and (Overlap is Low) and (Spot-size is High) and (Energy is High) then (Wear-rate is Medium) (1)

If (Scanning-speed is Low) and (Overlap is Medium) and (Spot-size is Medium) and (Energy is High) then (Amorphous-content is Low) (1) 
If (Scanning-speed is Low) and (Overlap is Medium) and (Spot-size is Medium) and (Energy is High) then (Amorphous-content is Low) (1)

If (Scanning-speed is Medium) and (Overlap is Medium) and (Spot-size is Low) and (Energy is Medium) then (Amorphous-content is Low) (1)

If (Scanning-speed is Medium) and (Overlap is High) and (Spot-size is High) and (Energy is Medium) then (Amorphous-content is Medium) (1)

1.2.3. Optimize and Minumize Wear Rate and Amorphous Content Values

Results of wear rate and amorphous content fuzzy systems that designed to implemented on FeCrMoCB MG samples shown in table 5. Optmium and minmum values of wear rate and amorphous content with scanning speed, overlap, spot size, and energy values appeared in Fig. $10(a, b, c)$ and Fig. 11 (a, b, c) respectively.

Table 5 Wear Rate and Amorphous Content Values

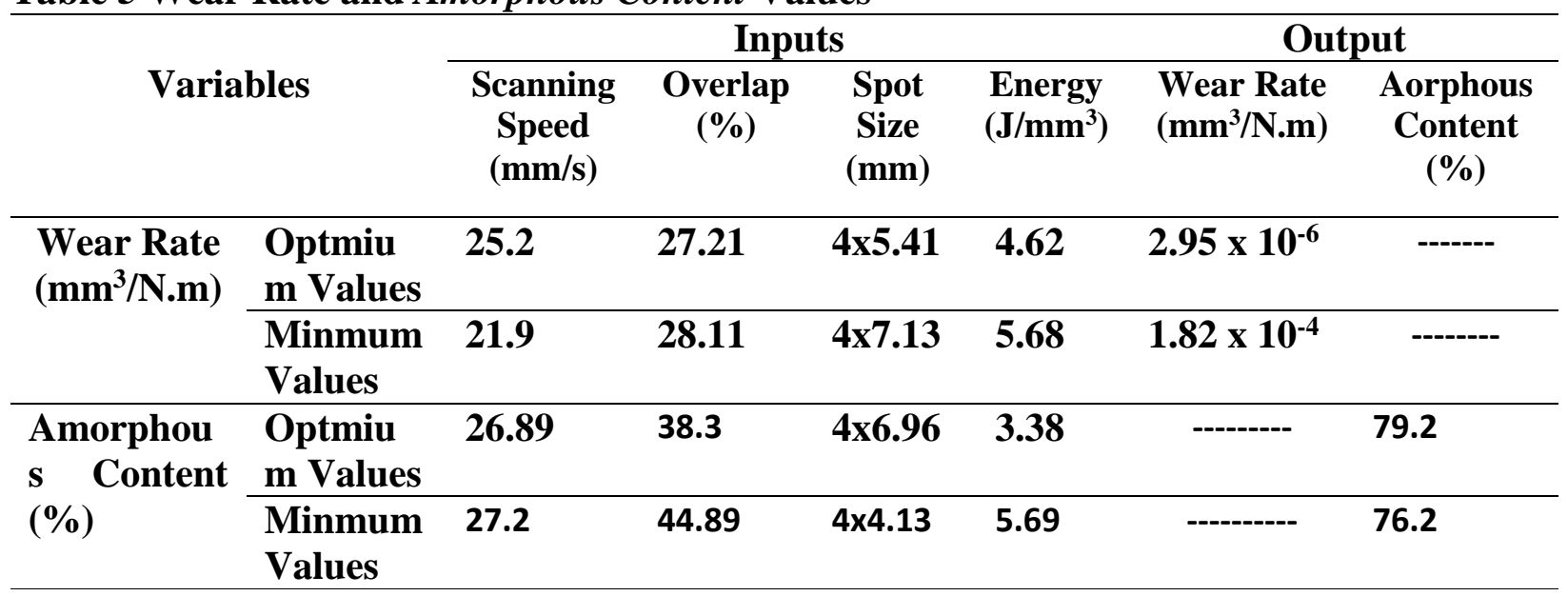

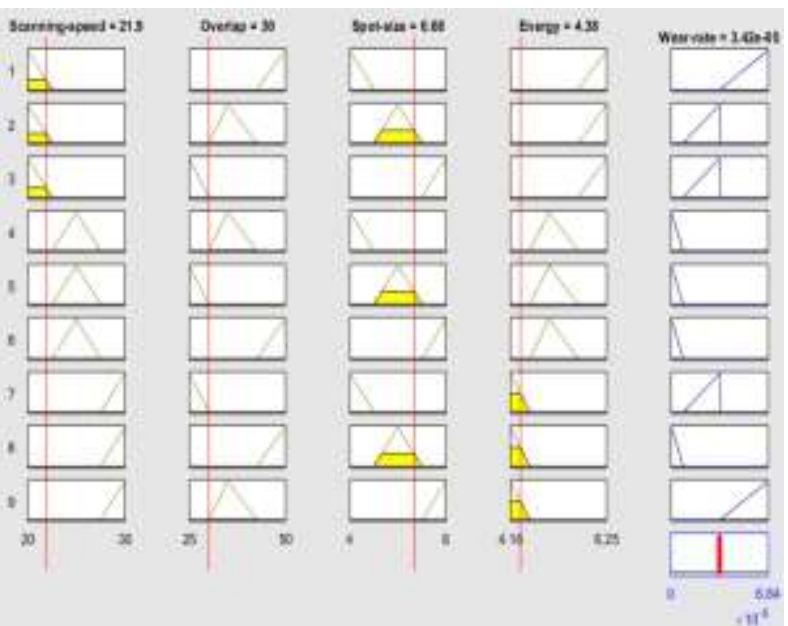

(a)
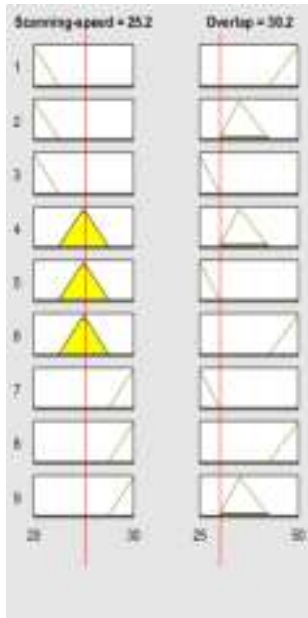

(b)

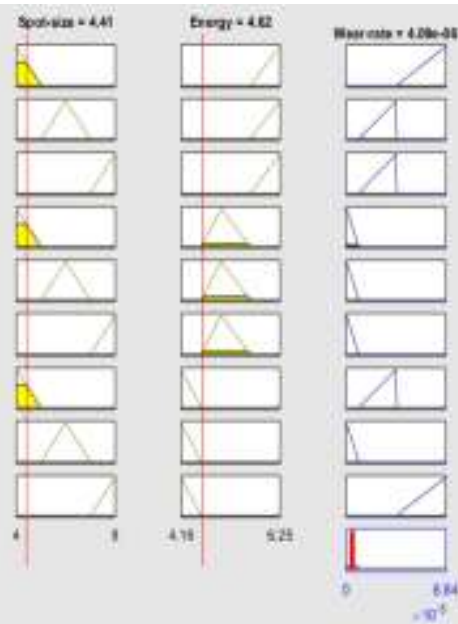




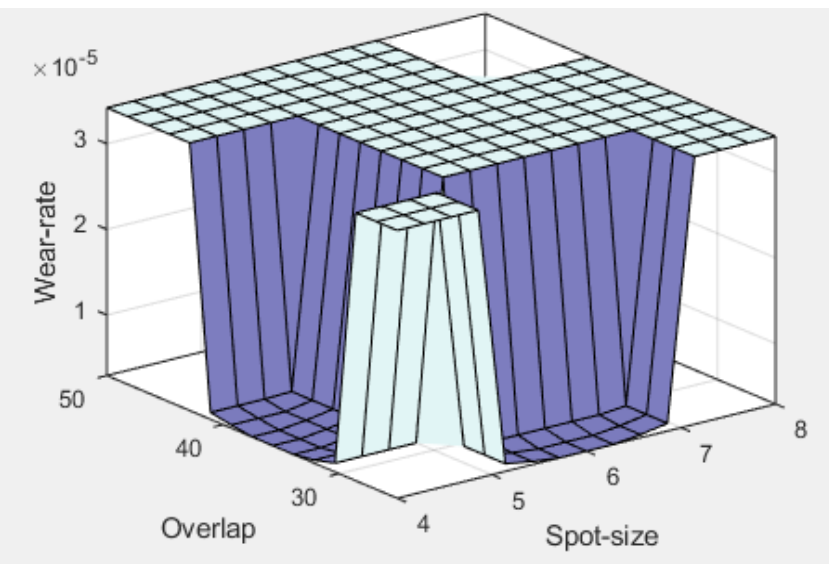

(c)

Fig. 10 Rules Viewer of Fuzzy System (a) Maximum Values, (b) Minimum Values, and (c ) Surface Viewer of Overlap, Spot Size with Wear Rate.

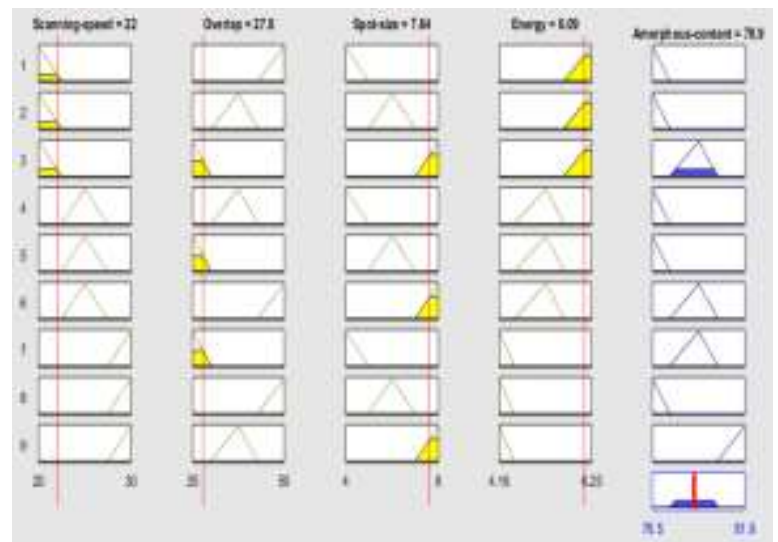

(a)
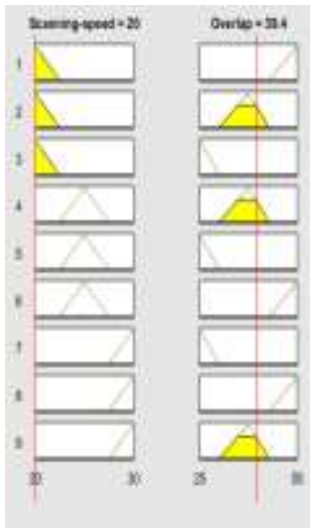

(b)
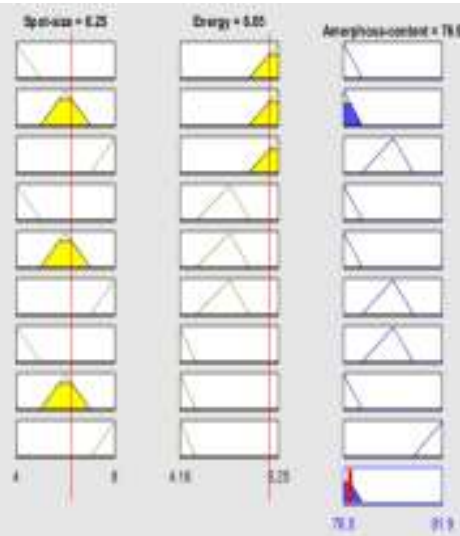

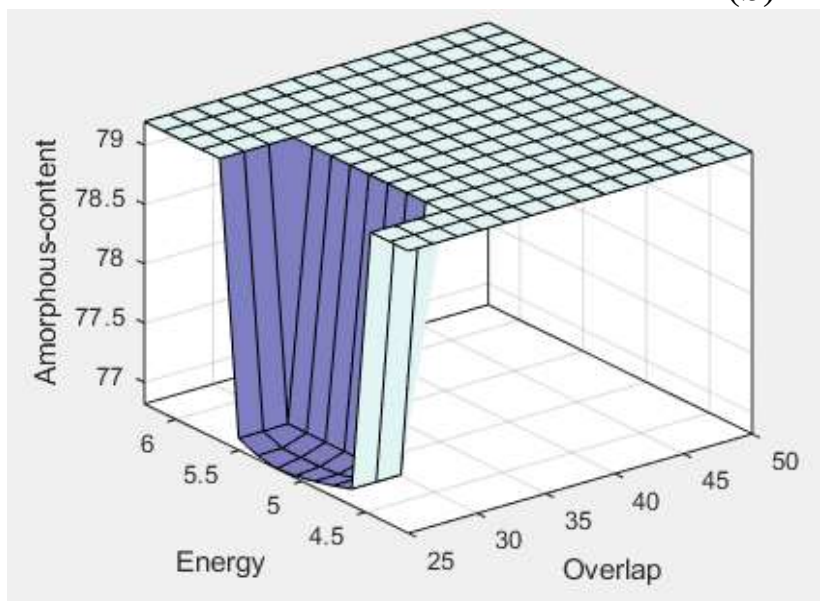

(c)

Fig. 11: Rules Viewer of Fuzzy System (a) Maximum Values, (b) Minimum Values, and (c) Surface Viewer of Overlap, Spot Size with Amorphous Content. 


\section{RESULTS AND DISCUSSION}

A comparison done between results of the designed wear rate, amorphous content fuzzy systems and experimental results, [8].

Table 6: Values of Wear Rate and Amorphous Content from Fuzzy Systems and Experimental Data

\begin{tabular}{ccccccccc}
\hline & \multicolumn{3}{c}{ Wear Rate $\left(\mathrm{mm}^{3} / \mathrm{N} . \mathrm{m}\right)$} & \multicolumn{3}{c}{ Amorphous Content (\%) } \\
\cline { 2 - 9 } Parameters & Experimental data & \multicolumn{2}{c}{ Fuzzy result } & \multicolumn{2}{c}{$\begin{array}{c}\text { Experimental } \\
\text { data }\end{array}$} & \multicolumn{2}{c}{ Fuzzy result } \\
\cline { 2 - 9 } & $\begin{array}{c}\text { Max. } \\
2.56 \times 10^{-6}\end{array}$ & $\begin{array}{c}\text { Min. } \\
1.28 \times 10^{-4}\end{array}$ & $\begin{array}{c}\text { Max. } \\
2.95 \times 10^{-6}\end{array}$ & $\begin{array}{c}\text { Min. } \\
1.82 \times 10^{-4}\end{array}$ & $\begin{array}{c}\text { Max. } \\
81.9\end{array}$ & $\begin{array}{c}\text { Min. } \\
76.5\end{array}$ & $\begin{array}{c}\text { Max. } \\
79.2\end{array}$ & $\begin{array}{c}\text { Min. } \\
76.2\end{array}$ \\
\hline $\begin{array}{c}\text { Scanning } \\
\text { Speed } \\
(\mathrm{mm} / \mathrm{s})\end{array}$ & 25 & 20 & 25.2 & 21.9 & 30 & 20 & 26.89 & 27.2 \\
\hline $\begin{array}{c}\text { Overlap } \\
(\%)\end{array}$ & 25 & 25 & 27.21 & 28 & 35 & 50 & 38.3 & 45.1 \\
\hline $\begin{array}{c}\text { Spot Size } \\
(\mathbf{m m})\end{array}$ & $4 \times 6$ & $4 \times 8$ & $4 \times 5.41$ & $4 \times 7.13$ & $4 \times 8$ & $4 \times 4$ & $4 \times 6.96$ & $4 \times 4.13$ \\
\hline $\begin{array}{c}\text { Energy } \\
\left(\mathrm{J} / \mathbf{m m}^{3}\right)\end{array}$ & 5 & 6.25 & 4.62 & 5.68 & 4.16 & 6.25 & 3.38 & 5.69 \\
\hline
\end{tabular}

Comparison between experimental data and fuzzy systems result appeared difference in wear rate, scanning speed, overlap, spot size, and energy were $15 \%, 1 \%, 8 \%, 9 \%$, and $9 \%$ respectively also from amorphous content fuzzy system the difference in amorphous content, scanning speed, overlap, spot size, and energy were 9\%, $10 \%, 9 \%, 13 \%$, and $18 \%$ respectively.

\section{CONCLUSIONS}

In this paper, wear rate and amorphous content of laser cladded FeCrMoCB metallic glass layer that developed on nickel-free stainless-steel were controlled using fuzzy logic control system. Two fuzzy logic control systems (wear rate fuzzy system and amorphous content fuzzy system) structed, designed, and implemented on experimented data of nine samples for optimize wear rate and amorphous content of that samples surface layer by controlling its machining conditions (scanning speed and overlap) and laser beam characteristic's (spot size and energy).

The fuzzy system acquired results Exhibit that fuzzy logic control system is a simple and unexpansive technology that can be used to predict and optimize laser cladding of metallic glasses. The results obtained prove the effectiveness and sufficiency of the proposed fuzzy logic control system.

\section{ACKNOWLEDGEMENT}

This research was funded by the Deanship of Scientific Research at Princess Nourah bint Abdulrahman University. 


\section{REFERENCES}

1. Piera Alvarez, M. Ángeles Montealegre, Jose F. Pulido-Jiménez and Jon Iñaki Arrizubieta, "Analysis of the Process Parameter Influence in Laser Cladding of 316L Stainless Steel", Journal of Manufacturing and Materials Processing, MDPI, (2018), doi:10.3390/jmmp2030055.

2. Payman Shayanfar, Habib Daneshmanesh, Kamal Janghorban, "Parameters Optimization for Laser Cladding of Inconel 625 on ASTM A592 Steel", Journal of Materials Research and Technology, Vol. 9, No. 4, pp. 8258 - 8265, (2020).

3. Jiang Ju, Yang Zhou, Maodong Kang and Jun Wang, "Optimization of Process Parameters, Microstructure, and Properties of Laser Cladding Fe-Based Alloy on 42CrMo Steel Roller", Material, MDPI, (2018), doi:10.3390/ma11102061.

4. Linsen, Bo Wang and Yayin HE, "Optimization of Process Parameters of Laser Cladding 304L Alloy Powder Based on Orthogonal Experiment", Journal of Mechanical Engineering Science, Vol. 1, No. 2, (2020), DOI:10.33142/me.v1i2.1656.

5. Jyoti Menghani, Akash Atulbhai and Satish R More, "Parametric investigation and optimization for $\mathrm{CO}_{2}$ laser cladding of AlFeCoCrNiCu powder on AISI 316", Journal of High Temperature Materials and Processes, Vol. 40, No. 1, pp. 265-280, (2021), DOI:10.1515/htmp - 2020 - 0075.

6. Meysar Zeinali, Amir Khajepour, "Development of an adaptive fuzzy logic-based inverse dynamic model for laser cladding process", Engineering Applications of Artificial Intelligence, Vol. 23, pp. 1408-1419, (2010).

7. Lei Che, Wenlei Sun, Guan Zhang, Jiaxin Han, "Optimization of Laser Cladding Process for Additive Repair of High Temperature and High-Pressure Valve Sealing Surface", Materials Science: Materials Review Vol. 2, No. 2, pp. 1-16, (2018).

8. Mahmoud Z. Ibrahim, Ahmed A.D. Sarhan, T.Y. Kuo, Farazila Yusof, M. Hamdi, and T.M. Lee, "Developing a New Laser Cladded FeCrMoCB Metallic Glass Layer on Nickel- Free Stainless-Steel as a Potential Superior Wear-Resistant Coating for Joint Replacement Implants", Surface \& Coatings Technology 392, 125755, (2020).

9. Pei, Y. T. \& Zuo, T. C., Gradient microstructure in laser clad TiC-reinforced Ni-alloy composite coating, Materials Science and Engineering, vol. 241, No. 1, pp. 259-263, (1998).

10. A. Frenk, M. Vandyoussefi, J.-D. Wagniere, A. Zryd, and W. Kurz, "Gradient microstructure in laser clad TiC-reinforced Ni-alloy composite coating, metallurgical and materials transactions", Vol. 28b, pp. 501-508, (1997).

11. Yanxiang Li and Jian Ma, "Study on overlapping in the laser cladding process, Surface and Coatings Technology", Vol. 90, Issues 1-2, 15 March 1997, pp. 1-5, (1997).

12. Haibo Huang, Wenlei Sun, Yong Huang and Jiangtong Yu, "Properties of Curved Parts Laser Cladding Based on Controlling Spot Size", Applied Sciences, MDPI, Appl. Sci. 2020, 10, 728; (2020), doi:10.3390/app10020728.

13. Steffen Nowotny, Frank Brueckner, Sebastian Thieme, Christoph Leyens and Eckhard Beyer, "High-performance laser cladding with combined energy sources, Journal of Laser Applications" - Laser Additive Manufacturing, Vol. 27, No. S1, pp. S17001, (1 - 8), (2015). 
14. Alexandre B. L., Egidio R. N, Industrial Application Control with Fuzzy Systems, International Journal of Innovative Computing, Information and Control, Vol. 12, No. 2, pp. 665 - 676, (2016).

15. Ying Bai, Dali Wang, Fundamentals of Fuzzy Logic Control - Fuzzy Sets, Fuzzy Rules and Defuzzifications, In book: Advanced Fuzzy Logic Technologies in Industrial Applications, pp. 17 - 36, (2007), DOI: 10.1007/978-1-84628-469-42.

16. A. Nagoor Gani, S. N. Mohamed Assarudeen, "A New Operation on Triangular Fuzzy Number for Solving Fuzzy Linear Programming Problem”, Applied Mathematical Sciences, Vol. 6, No. 11, pp. 525 - 532, (2012). 